\title{
Mitochondrial Disorders Therapy: The Utility of Melatonin
}

\author{
Luis C. López ${ }^{1,2}$, Darío Acuña-Castroviejo ${ }^{1,2,3}$, Alberto del Pino ${ }^{1,2}$, Miguel Tejada ${ }^{1,2}$ and \\ Germaine Escames ${ }^{*}, 1,2$ \\ ${ }^{I}$ Instituto de Biotecnología, Centro de Investigación Biomédica, Universidad de Granada, Granada, Spain \\ ${ }^{2}$ Departamento de Fisiología, Facultad de Medicina, Universidad de Granada, Granada, Spain \\ ${ }^{3}$ Servico de Análisis Clínicos, Hospital Universitario San Cecilio, Granada, Spain
}

\begin{abstract}
Mitochondria play a central role in the cell physiology. It is now recognized that, besides their classic function of energy metabolism, mitochondria are enrolled in multiple cell functions including energy distribution through the cell, energy/heat modulation, reactive oxygen species (ROS) regulation, calcium homeostasis, and apoptosis control. Recently, evidence is accumulating for a direct participation of mitochondria in stem cell proliferation and/or differentiation. All these functions suggest that mutations in either nuclear or mitochondrial DNA may induce serious cell impairments, and there is now evidence of more than $200 \mathrm{mtDNA}$ mutations responsible for human pathologies. Moreover, mitochondria are, simultaneously, the main producer and target of ROS and, thus, multiple mitochondrial diseases are related to ROSinduced mitochondrial injuries. Among these, neurodegenerative diseases such as Parkinson's disease (PD), Alzheimer's disease (AD), inflammatory diseases such as sepsis, and aging itself, are caused or accompanied by ROS-induced mitochondrial dysfunctions. With regard to its action spectrum as an antioxidant, melatonin may be regarded as a firstchoice agent for preventing and/or reducing the excess of ROS, thereby maintaining mitochondrial homeostasis. Multiple in vitro and in vivo experiments have shown the protective role of melatonin on mitochondrial physiology, yielding a significant improvement in those diseases in which energy supply to the cell had been compromised. New lines of evidence suggest the participation of mitochondria in stem cell proliferation and differentiation, and preliminary data support the role of melatonin in these processes. This review accounts for the multiple functions of mitochondria and the mechanisms involved in the numerous beneficial effects of melatonin to maintain mitochondrial homeostasis.
\end{abstract}

Keywords: Oxidative stress, aging, mitodhondrial dysfunction, neurodegenerative diseases, stem cell differentiation, melatonin therapy.

\section{MITOCHONDRIAL FUNCTION}

Mitochondria are organelles found almost ubiquitously in eukaryotes. Their small size contradicts their fundamental magnitude to the life and metabolic economy of the cell, as they are the location of a number of vitally important metabolic pathways including Krebs cycle, fatty acid oxidation, and lipid and cholesterol synthesis. Most of these are "housekeeping" functions that are required for the maintenance of the cell's well-being. Foremost among these is formation of ATP, a versatile carrier of energy, in the respiratory chain/oxidative phosphorylation system. This aspect of mitochondrial function is unique insofar as the transformation of chemically bound energy is based on genes encoded in both mitochondrial and nuclear DNA. By virtue of possessing their own genome - mitochondrial DNA (mtDNA) - mitochondria are distinctive mammalian organelles. Human mtDNA is a 16,569 base pair, double stranded, circular molecule, which is maternally inherited [1]. MtDNA is continuously replicating in both dividing and non-dividing cells. Several nDNA-encoded proteins and

*Address correspondence to this author at the Centro de Investigación Biomédica, Parque Tecnológico de Ciencias de la Salud, Avenida del Conocimiento s/n, 18100 Armilla, Granada, Spain; Tel: +34958241000 , Ext. 20197; Fax:+34958819132; E-mail: gescames@ugr.es other factors are involved in regulating human mtDNA replication and transcription [2]. The two strands of mtDNA have different densities determined by their $\mathrm{G}+\mathrm{T}$ content and are described as heavy $(\mathrm{H})$ and light $(\mathrm{L})$ strands. Most of the information is encoded on the heavy (H) strand, with genes for two ribosomal RNAs (rRNAs), 14 transfer RNAs (tRNAs), and 12 polypeptides. The light (L) strand codes for 8 tRNA, and a single polypeptide. All thirteen polypeptides are subunits of the respiratory chain/oxidative phosphorylation system: seven belong to Complex I (C-I) or NADH$\mathrm{CoQ}$ oxidoreductase), one to Complex III (C-III) or CoQcytochrome $c$ oxidoreductase, three to Complex IV (C-IV) or cytochrome $c$ oxidase (COX) and two to Complex V (C-V) or ATP synthase. These subunits are synthesized within the mitochondrion, where they assemble with a larger number of subunits encoded by nuclear DNA (nDNA) that are synthesized in the cytoplasm and are transported into mitochondrion [3]. The five mitochondrial complexes together with two electron carriers, coenzyme Q10 ( $\left.\mathrm{CoQ}_{10}\right)$ and cytochrome c, are embebed in the inner mitochondrial membrane, which is rich in cardiolipin, an unusual phospholipid directly involved in the mitochondrial function [4].

$\mathrm{NADH}+\mathrm{H}^{+}$and $\mathrm{FADH}_{2}$ produced by glycolysis, Krebs cycle, and $\beta$-oxidation of fatty acids are oxidized by the respiratory chain transferring electrons from these precursors 
to $\mathrm{O}_{2}$. Incomplete reduction of oxygen occurs by electron leakage from especially $\mathrm{C}$-I and $\mathrm{C}$-III, perhaps also from $\mathrm{C}$ IV. The resulting superoxide anion, $\mathrm{O}_{2} \bullet^{-}$, is the source of other reactive intermediates, $\mathrm{H}_{2} \mathrm{O}_{2}$ and $\mathrm{HO} \cdot$. These three molecules, which represent endogenous oxidotoxins, are collectively denoted as reactive oxygen species (ROS). They can be detoxified by the antioxidant defense system that includes superoxide dismutase (SOD), glutathione redox cycle, catalase and melatonin [5]. According to the chemiosmotic hypothesis [6], the free energy made available in the course of sequential electron transfer is used by C-I, C-III and C-IV to pump protons from the matrix to the intermembrane space. This results in a proton gradient $\left(\Delta \mu_{\mathrm{H}}^{+}\right)$over the mitochondrial inner membrane. This proton gradient is a source of free energy that is dissipated when protons enter the inner mitochondrial membrane via the ATP synthase. During this process, ADP is phosphorylated to ATP, a high energy molecule consumed by many enzymes and numerous cellular processes [6]. Dissipation of energy as heat to maintain body temperature at a level higher than in the environment is another important function of mitochondria. The mechanism is called thermoregulating uncoupling of respiration and phosphorylation, and this function seems to depend on the so-called uncoupling proteins (UCPs) [7]. UCPs are proton transporters across the inner mitochondrial membrane, driven only by the membrane potential [8]. Five types of UCPs have been identified in mammals, UCP1, $\mathrm{UCP} 2, \mathrm{UCP} 3, \mathrm{UCP} 4$ and UCP5, and they constitute a subfamily within the gene family of mitochondrial anion carriers [9]. While UCP1 is known to play an important role in regulating heat production during cold exposure in some mammals including human babies, possible roles for other UCPs are still controversial and they may include the control of ROS production by mitochondria [10,11]. These UCPs probably do not transport protons except in the presence of specific activators [12]. Fatty acids, ROS and free-radicalderived alkenals are activators of proton transport through UCPs, whereas purine nucleotides are inhibitory $(10 ; 11)$. CoQ has been also proposed as a regulatory factor of UCPs but the results are still controversial [13-16]. A failure to control ROS damage can induce the collapse of multiple vital functions, including mitochondrial energy conservation, which culminates in loss of membrane integrity and cell death by necrosis and/or apoptosis [7]. The UCP-dependent uncoupling leads to suction of electrons and, consequently, reduces electron overflow and, thus, superoxide formation [17]. Thus, uncoupling can reduce the probability of mitochondrial permeability transition pore (mtPTP) opening and should, therefore, prevent the proapoptotic cascade.

Mitochondria play also an important role in the signaling for apoptotic cell death. Apoptosis may be initiated in the course homeostatic regulation, aging, mitochondrial dysfunction and to eliminate potentially tumorigenic cells. Mitochondria promote the release of proapoptotic factors including cytochrome $c$ in the intermembrane space [18], activating the apoptotic cascade [19]. The PTP may be regulated by the ROS leaking from the ETC. A shift from a low to a high-conductance state is promoted by the oxidation of NADPH by oxidative stress. This impairs the antioxidant function of glutathione (GSH) [20]. The participation of ROS in the opening PTP is supported by the fact that this pore remains closed in the absence of molecular oxygen
[20]. The PTP possesses at least two redox-sensitive sites which increase the probability of opening after oxidation: the S-site, a dithiol in apparent redox equilibrium with matrix $\mathrm{GSH}$, and the P-site, in apparent redox equilibrium with the pyridine nucleotides [21]. Oxidized glutathione (GSSG) is probably the immediate oxidant of the S-site and many inducers of pore opening such as hydrogen peroxide $\left(\mathrm{H}_{2} \mathrm{O}_{2}\right)$ appear to affect the pore through changes at the level of GSH rather than the direct oxidation of the S-site. In turn, oxidation of the P-site by oxidized pyridine nucleotides can induce PTP opening under conditions where the GSH pool is maintained in a fully reduced state. Under conditions of oxidative stress, the mitochondrial levels of GSH and reduced pyridine nucleotides are connected through energylinked transhydrogenase and glutathione reductase (GRd) and thus it is difficult for these compound to independently modulate the $\mathrm{S}-$ and the $\mathrm{P}$-site in vivo [21].

\section{PRIMARY MITOCHONDRIAL DISORDERS}

Primary respiratory chain defects are caused by mutations in mtDNA or nDNA genes that encode subunits of the mitochondrial respiratory chain. About $200 \mathrm{mtDNA}$ point mutations have now been associated with human diseases, whereas only a small but increasing number of nDNA gene mutations have been identified [22].

Mutations in mtDNA protein-coding genes include mutations in ATP6 causing neuropathy, ataxia, retinitis pigmentosa (NARP) or maternally inherited Leigh syndrome (MILS) [22, 23]; mutation in ATP8 causing hypertrophic cardiomyopathy and nephropathy [24]; mutations in ND1, ND4 and ND6 causing Leber hereditary optic neuropathy (LHON); and mutations in ND1, ND4, cyt b, COXI, COXII or COXIII causing myopathy, encephalopathies, multisystemic diseases or another phenotypes [22, 23]. mtDNA deletions are frequently associated with chronic progressive external ophthalmoplegia (CPEO) or with Kearns-Sayre syndrome. mtDNA deletions and duplications are also associated with diabetes and myopathy [22, 23].

The most common mtDNA tRNAs mutations are the $3243 \mathrm{~A}>\mathrm{G}$ tRNA ${ }^{\mathrm{Leu}}$ causing mitochondrial encephalomyopathy, lactic acidosis, and stroke-like episodes (MELAS); and the $8344 \mathrm{~A}>\mathrm{G}$ tRNA ${ }^{\text {Lys }}$ causing myoclonic epilepsy with ragged red fibers (MERRF). In addition, a large number of tRNAs mutations have been associated with different phenotypes including myopathy, cardiomyopathy, encephalopathy, Leigh syndrome, deafness and diabetes $(22 ; 23)$. Mutations in $12 \mathrm{~S}$ and $16 \mathrm{~S}$ rRNAs have been associated with deafness and/or cardiomyopathy [22, 23].

Mutations in nDNA genes encoding mitochondrial respiratory chain subunits have been identified in a few cases, relative to the pertinent numerous mtDNA mutations known. Consequently, it has been suggested that most deleterious mutations in these nDNA genes are incompatible with life. The reported cases are mutations in C-I subunits (NDUFA1; NDUFS1,2,3,4,6,7,8; and NDUFV1,2) causing Leigh syndrome and leukodystrophy [22, 23]; mutations in $\mathrm{SDH}$ subunits (SDHA,B,C,D) yielding Leigh syndrome and ataxia $[22,23]$; mutation in the UQCRB subunit of C-III producing Leigh syndrome [25]; and mutation in the COX6B1subunit of CIV causing severe encephalopathy [26]. 
In mtDNA-related mitochondrial encephalomyopathies, cells die because the lack of an adequate energy supply and the decrease in $\Delta \psi_{\mathrm{m}}$ that triggers PTP opening and apoptosis. However, a relatively small number of non-mutated mitochondrial chromosomes seems to be sufficient for protecting cells from respiratory chain defects. In neurons, the incapacity to maintain adequate ATP levels would lead to a partial neuronal depolarization and excitotoxicity, and muscle cells seem to die mainly by apoptosis [22]. In addition, oxidative stress can also participate to a variable extent in the pathology of primary mitochondrial disorders. Transmitochondrial cybrids harbouring homoplasmic mutations in mitochondrial tRNA genes (A3243G in tRNA LeuUUR and A8344G in tRNA Lys) showed an increase of ROS production and an increase in the antioxidant enzyme activities when they were grown under glucose-rich medium [27]. In contrast, homoplasmic COX mutant cybrids (carrying the stop-codon mutation G6930A in the COXI gene) grown under similar conditions did not show any sign of oxidative stress [27]. By contrast, cybrids harbouring homoplasmic mutations (Leber's hereditary optic neuropathy mutations) in mtDNA encoding subunits of complex I, ND1, ND4 and ND6, showed alterations of the antioxidant defense when the cells were grown in galactose medium (which forces ATP production through oxidative phosphorylation [28], but not under glucose-rich medium [29]. Likewise, mutations in ATP6 (T8993G and T8993C) have shown variable grade of oxidative stress depending on the severity of the mutation, degree of heteroplasmy or/and the culture conditions [30]. Therefore, the involvement of oxidative stress in the pathology of primary mitochondrial disorders seems to depend of the severity of the mutation, the heteroplasmy level and the energy requirement of the cell.

\section{SECONDARY MITOCHONDRIAL DISORDERS}

Secondary respiratory chain defects may encompass all the etiologies other than primary gene mutations of respiratory chain subunits. It can include defects of nuclearencoded mitochondrial proteins responsible for the synthesis of components of the mitochondrial respiratory chain, the assembly of respiratory chain complexes, mtDNA integrity, replication and transcription, transport of nuclear-encoded proteins, regulation of the composition of mitochondrial membranes, mitochondria fusion and fission, proteins involved in critical mitochondrial biochemical pathways, and general intracellular biochemical derangements that have an impact on mitochondrial respiratory chain function [22, 23].

The biosynthesis of $\mathrm{CoQ}_{10}$ is carried out in the mitochondrial inner membrane and at least 8 enzymes participate in this process [31]. Mutations in the genes that encode these enzymes are responsible of primary $\mathrm{CoQ}_{10}$ deficiency, an autosomal recessive syndrome with a clinical spectrum that encompasses five major phenotypes [31]. Although it was already described 30 years ago, molecular defects were identified only recently. Specifically, the first mutations in two genes encoding the initial two $\mathrm{CoQ}_{10}$ biosynthetic enzymes (PDSS2 subunit of COQ1, and COQ2) were identified in infants or children with encephalomyopathy or Leigh syndrome and nephrotic syndrome [32, 33]. Later, mutations in PDSS1 and others in COQ2 were indentified in infants or children with encephalomyopathy and/or nephrotic syndrome $[34,35]$. Recently, a mutation in $C O Q 9$, a $\mathrm{CoQ}_{10}$ biosynthetic gene with unknown function, was identified in a child with intractable seizures, global developmental delay, hypertrophic cardiomyopathy and renal tubular dysfunction [36]. Nevertheless, the consequences of primary $\mathrm{CoQ}_{10}$ deficiency include a severe bioenergetic defect or a combination of mild bioenergetic defect and oxidative stress, which seems to be dependent on $\mathrm{CoQ}_{10}$ levels [37]. Other syndromes have also been associated with a secondary $\mathrm{CoQ}_{10}$ deficiency. These include autosomal recessive cerebellar ataxia of unknown etiology in children and is caused by mutations in $A D C K 3$ in adults [31, 38], the syndrome of ataxia and oculomotor apraxia (AOA1) caused by mutations in the aprataxin gene $(A P T X)[39]$, and a predominantly myopathic form of glutaric aciduria type II (GAII) caused by mutations in the electron transfer flavo-protein dehydrogenase gene $(E T F D H)$ [40]. The usual treatment of $\mathrm{CoQ}_{10}$ deficient patients is the oral supplemen-tation with $\mathrm{CoQ}_{10}$. However, the cause of the lack of positive response in some patients requires investigation $[31,32,35,36,38]$.

The most frequent mutation in assembly factor genes have been identified in patients with COX deficiency associated with Leigh syndrome, myopathy and encephalopathy. These are the cases of mutations in COX10, COX15, LRPPRC, SCO1, SCO2 and SURF1 [22, 23]. Mutations in assembly factors for other mitochondrial complexes include the NDUFA12L gene resulting in defective assembly of C-I [22, 23]; SDHAF1 producing defective assembly of C-II [41]; BSC1L gene resulting in defective assembly of C-III $[22,23]$; and ATPAF2 gene producing defective assembly of $\mathrm{C}-\mathrm{V}[22,23]$.

mtDNA integrity, replication and transcription depend on several nDNA-encoded proteins. Then, mutations in these nDNA genes yield quantitative or qualitative abnormalities of mtDNA. A quantitative mtDNA alteration is a partial or severe mtDNA depletion which frequently causes myopathy or hepatopathy. A particular disease in this category is MNGIE (mitochondrial neurogastrointestinal encephalomyopathy) since a combination of mtDNA depletion, multiple mtDNA deletions and point mutations are found in many organs of MNGIE patients [42-44]. The primary cause of the disease is a mutation in TYMP gene [42], which encodes thymidine phosphorylase (TP), an enzyme that catalyzes the phosphorolysis of thymidine and deoxyuridine. A defect in the function of TP causes an accumulation of thymidine and deoxyuridine provoking an unbalance in the mitochondrial deoxynucleotides pool, which in turns causes mtDNA alterations [45].

The vast majority (99\%) of the mitochondrial proteins are encoded by nDNA genes, so they have to be imported from the cytoplasm into mitochondria. Mitochondrial proteins synthesized in the cytoplasm possess mitochondrial targeting signals that direct them to the appropriate compartment within the organelle. Transport across outer and inner membranes requires a well coordinated machinery that include docking proteins, chaperonins, and proteases, and it involves unfolding and refolding of the protein to be translocated. Thus, mutations in the mitochondrial targeting signals and defects in the import machinery cause fails in the nuclear-coded protein transport into mitochondria [22]. 
The mitochondrial respiratory chain complexes are embedded in the lipid milieu of the inner mitochondrial membrane. Therefore, alterations or damage in the inner mitochondrial membrane may affect mitochondrial function. The inner mitochondrial membrane is rich in cardiolipin, an unusual phospholipid directly involved in the mitochondrial function. Alteration in the concentration and composition of cardiolipin leads to altered mitochondrial architecture and function. These changes are representative of Barth syndrome, an X-linked recessive disorder characterized by mitochondrial myopathy, cardiomyopathy, and growth retardation, and caused by mutations in the gene encoding a phospholipid acyltransferase called tafazzin (TAZ) [22].

Mitochondria are dynamic organelles and form tubular networks that may favor the delivery of ATP to areas of high energy demands. Then, defects in proteins responsible of mitochondrial motility-fusion-fission cause another group of mitochondrial disorders. At least mutations in 13 different genes, i.e. OPA1, MFN2 and GDAP1, have been associated with defects in mitochondrial dynamics [22].

Finally, secondary respiratory chain defects also include secondary consequence of other factors such as the generation of reactive oxygen and nitrogen species (ROS and RNS, respectively) and the subsequent widespread deleterious effects (oxidation and/or nitrosylation of DNA, lipids and proteins) of these intermediates. The generation of toxic reactive intermediates has been implicated in aging and a number of relatively common disorders, including neurodegenerative diseases, sepsis, diabetes and cancer.

\section{PATHOLOGIES ASSOCIATED WITH MITOCHON- DRIAL IMPAIRMENT}

Sepsis is a systemic inflammation characterized by the activation of a number of intracellular signaling pathways; some of these signals lead to the expression of inducible nitric oxide synthase (iNOS). The iNOS produces nitric oxide (NO•), a crucial molecule in the inflammatory response because of its vasodilator properties and bactericide action [46, 47]. However, the excessive and prolonged production of $\mathrm{NO} \cdot$ has toxic effects in the organism $[46,47]$. In mitochondria, $\mathrm{NO} \cdot$ can inhibit mitochondrial respiratory chain complexes and compete with oxygen for its binding site to complex IV [48, 49]. In experimental models of sepsis, it has demonstrated that huge amounts of NO• produced by iNOS are responsible of mitochondrial dysfunction and increased oxidative damage in different tissues [50-54]. The result is a bioenergetic crisis that contributes to the mortality of septic patients $[55,56]$.

Neurodegenerative diseases of different etiologies may share mitochondrial dysfunction, oxidative/nitrosative stress and apoptosis in particular brain areas as a final common pathway. Mitochondrial involvement in Parkinson's disease (PD) is revealed by deficiency of mitochondrial complex I (C-I) in substantia nigra [57], with a parallel reduction in GSH levels, suggesting the existence of oxidative stress. In platelets of PD patients C-I is also decreased, and in some cases, this is accompanied by C-II, C-III and C-IV deficiencies. Studies with cybrids have shown that alterations in C-I is due to a defect in the mtDNA [57]. Mitochondrial involvement in the pathology of PD has been genetically supported by the finding of $P O L G$ mutations in early-onset Parkinsonism in different families [58, 59]. However, there is currently no convincing proof for a primary role of mtDNA mutations in this neurodegenerative disorder [60]. However, a series of nuclear genes (PARK2, PARK7, PINK1, SNCA, LRRK2 and HTRA2) has been found to be associated with the familial form of PD [22]. Moreover, some environmental toxins seem to interact with the products of these genes, which provokes oxidative damage, mitochondrial dysfunction and cell death [61]. These toxins including 1-methyl-4-phenyl-1,2,3,6-tetrahydropyridine (MPTP), rotenone and paraquat, cause mitochondrial dysfunctions comparable to those in PD, stimulate nNOS activity and $\mathrm{NO} \cdot$ production [62], and decrease the content of mtDNA [63].

Mitochondria are also involved in the pathology of Alzheimer's disease (AD), including reduction in brain energy metabolism [64], defects of mitochondrial metabolic enzymes $[65,66]$, and deficiencies of respiratory chain complexes $[67,68]$. In a recent study, female triple transgenic Alzheimer's mice (3xTg-AD) showed an early mitochondrial bioenergetic deficit and increased oxidative stress in brain which were exacerbated in the reproductive senescence [69]. However, thorough analyses found little evidence in support for a role of mtDNA mutations in the development of $A D$ [60]. Furthermore, it has been shown that $\beta$-amyloid peptide generates ROS in a metal-catalyzed reaction, which induces neuronal cell death in a ROS-mediated process resulting in damage to neuronal membrane lipids, proteins and nucleic acids.

Aging has been also related to the increased oxidative damage and mitochondrial dysfunction [70, 71]. mtDNA point mutations and duplications in tRNA, protein-coding genes and D-loops have been found to accumulate in some post-mitotic tissues during human aging [72-74]. However, it seems that the proportion of mutant mtDNAs is too low to cause a significant impact on mitochondrial function in aging tissues. On the other hand, the distribution of the mutant mtDNA in the cell and tissue is still unknown and the answer to this matter could resolve important questions regarding the importance of mtDNA mutation in aging [75]. Additionally, mitochondrial polymerase $\gamma$ (POLG) deficient mice accumulate high levels of mtDNA mutations resulting in a premature aging phenotype without increase of ROS generation and oxidative damage [76, 77]. These results would support the idea of a direct involvement of mtDNA mutations in aging but would cast doubt on the vicious cycle theories of aging and oxidative stress [78]. However, some explanations have been proposed to account the lack of oxidative stress in POLG deficient mice: aging is the result of alterations in many pathways; alterations in POLG may be downstream from mechanisms that generate ROS; and extensive mtDNA mutations could prevent the generation of ROS [78]. Contrary to the POLG mutator mice, skin fibroblasts harboring an mtDNA point mutation associated with aging show an alteration in the expression profile of antioxidant enzymes [79]. Age-related mtDNA deletions have been also detected in humans with a dissimilar pattern in different tissues [80], and the correlation of the increased of mtDNA deletions and mitochondrial respiratory chain malfunction during aging has been amply reported [81-83]. The mechanisms of mtDNA deletions during aging are still 
controversial but oxidative damage to DNA associated with single- or double-strand breaks has been proposed. This idea has been supported by some studies: the relative amount of mtDNA deletions correlates with the levels of 8-hydroxy-2'deoxyguanosine $(8-\mathrm{OHdG})[84]$; and treatment of human skin fibroblasts with sub-lethal dose of oxidants and environmental insults inducers of ROS results in the formation and accumulation of the $4977 \mathrm{bp}$ deletion in mtDNA $[85,86]$. Oxidative damage in aging is also reflected by oxidation of mitochondrial proteins in a variety of arganisms [75]. Proteins containing Fe-S clusters seem to be the most susceptible to oxidation [75]. Several reports have revealed that oxidation of aconitase, adenine nucleotide translocase and mitochondrial respiratory chain complexes increase during aging and, consequently, the activities of these enzymes may diminish [87-89]. Oxidative injury is not limited to mtDNA or proteins but is also detected in mitochondrial membranes. This may lead to a progressive lipid peroxidation (LPO) and cross-linking damage, with simultaneous changes in the respiration rate, ATP synthesis, membrane fluidity and permeability, $\mathrm{Ca}^{2+}$ homeostasis and apoptosis [90]. Alterations in the expression and activities of the antioxidant enzymes in response to the oxidative environment in the aging cells has been found in human blood [91-93] and muscle [94, 95], and in a variety of tissues from rats and mice, including skeletal muscles, brain and heart, which are tissues with high energy demand. Additional information about the physiological changes in mammalian aging has been obtained in studies performed in the senescence-accelerated mouse (SAM) [96]. SAM includes two strains, one prone to accelerated senescence (SAMP) and one resistant to accelerated senescence (SAMR). SAMP8, a sub-strain of SAMP, shows relatively strain specific age-associated phenotypic pathologies such as a shortened life span and early manifestation of senescence (including loss of activity, alopecia, lack of hair glossiness, skin coarseness, periophthalmic lesions, increased lordokyphosis and systemic senile amyloidosis), similar to several geriatric disorders observed in humans [96, 97]. SAMP8 mice show a general hyperoxidative status manifested by increased mitochondrial electron leakage and ROS production, increased LPO and protein carbonyl content, changes in the antioxidant enzymes activities and increase of GSSG: GSH ratio [98-104]. The results are a decrease in the mitochondrial respiratory chain activity, ATP synthesis and energy status of the organism, suggesting that the mechanism of senescence acceleration in SAMP8 mice is related to free radical damage in a variety of tissues [105-107]. SAMP8 mice also show an age-dependent increase in IFN- $\gamma$ and TNF- $\alpha$, a reduction in IL- 2 levels and an increase on nitric oxide $(\mathrm{NO} \bullet)$ levels [108], suggesting the existence of an inflammatory process during aging. The increase in NO• levels is particularly relevant since this radical can react with $\left(\mathrm{O}_{2}^{-\bullet}\right)$ in mitochondria yielding peroxynitrite [109], which irreversibly impairs the mitochondrial respiratory chain and decreases the efficiency of the oxidative phosphorylation, leading to energy depletion and cell death [49, 110].

\section{MITOCHONDRIA AND STEM CELLS}

Stem cells are classified depending on their capacity of differentiation to mature cells, processes which are regulated by many factors. In the last years, some studies have lead to propose a mitochondrial involvement in the regulation of pluripotency and differentiation of stem cells. Differentiation of mouse and human embryonic stem cells (ESC) results in changes in mitochondrial structure, morphology and pattern of cytoplasmic localization. Mitochondria in stem cells tend to localize perinuclearly [111]. Moreover, ESC have relatively few mitochondria with poorly developed cristae $[112,113]$, and restricted oxidative capacity. As cells are allowed to differentiate, the mtDNA copies are amplified and the differentiated cells contain larger numbers of mitochondria with distinct cristae, dense matrices and high membrane potentials. These features suggest the initiation of metabolic activity through OXPHOS [114]. Because ESC display low oxygen consumption and thus, poor OXPHOS, an elevation in ATP content per cell may therefore reflect a loss of stemness and the subsequent onset of differentiation $[111,113]$. Remarkably, transmitochondrial embryonic stem cells harboring pathogenic mtDNA mutations have shown to be compromised in neuronal differentiation when the mitochondrial respiratory chain function is severely affected [115]. Therefore, preservation of immature mitochondria with a perinuclear arrangement, reduced expression of OXPHOS enzymes and low metabolic activity in ESC has led to the suggestion that these mitochondrial properties might be important for the maintenance of pluripotency and should be considered as another ESC marker.

The increase in mitochondrial mass is accompanied by elevated ATP production and, thus, by a greater generation of ROS. Undoubtedly, the intracellular levels of ROS are higher in differentiated than in undifferentiated cells, due to the increase in OXPHOS metabolism in the former [116]. An increase in ROS levels might have a role in cell signaling and regulation of proliferation and differentiation. Exposure to low levels of ROS has been reported to enhance ESC differentiation whereas continuous exposure to high levels of ROS results in inhibition of differentiation [116]. Therefore, differentiating cells probably activate effective antioxidant systems, including catalase, glutathione peroxidase (GPx) and others. However, a recent study has revealed high levels of ROS in Drosophila multipotent haematopoietic progenitor cells. The ROS levels are decreased when the progenitor cells undergo differentiation. And interestingly, this differentiation can be modulated by scavenging or increasing the ROS [117]. In summary, successful differentiation of embryonic cells in vivo or ESC in vitro involves initiation of mtDNA transcription and replication, an increase in the number of mitochondria, and regulation of the enzymes required for aerobic metabolism in order to fulfill the elevated ATP requirements of fully differentiated cells. Additionally, ROS and antioxidant defenses may also be involved in the regulation of the differentiation.

\section{THE ANTIOXIDANT CAPACITY OF MELATONIN AND ITS ACTIONS ON MITOCHONDRIA-RELATED DISORDERS}

Melatonin is an ancient indoleamine derived from tryptophan, present from unicellular organisms to mammals $[118,119]$. In mammals, melatonin is synthesized by the pineal gland in a circadian manner and it is released to the 
blood, where it can attain up to $0.5 \mathrm{nM}$ [120]. Melatonin is also produced in most of the tissues and organs of the body and this extrapineal biosynthesis of melatonin is, in total, much higher than that formed by the pineal $[121,122]$. The different sources of melatonin are related to the different actions of the indoleamine: the pineal melatonin is mainly a mediator of the circadian cycles and circannual reproductive rhythms $[123,124]$; the extrapineal melatonin participates in the immune system modulation, anti-inflammatory mechanisms and antioxidant actions [5, 125]. Interestingly, melatonin is concentrated by subcellular compartments including nucleus and mitochondria, the latter showing 100-200 times more melatonin than cytosol $[126,127]$. Therefore, melatonin is available in the mitochondrion, the cell organelle in which free radicals are being maximally generated, and can counteract a potential damage $[128,129]$.

The earliest evidences of the antioxidant capacities of melatonin were reported in the $90^{\prime}$ s. First, it was shown that one molecule of melatonin scavenges two molecules of $\mathrm{HO}$, producing in that reaction cyclic 3-hydroxymelatonin [130, 131]. This molecule can be detected in the urine of human and rats under oxidative stress conditions and treated with melatonin [131]. Moreover, several oxidative pathways of melatonin yield $N^{1}$-acetyl- $N^{2}$-formyl-5-methoxykynuramine (AFMK) [132]. Although it was proposed that AFMK is a byproduct of the interaction of melatonin with $\mathrm{H}_{2} \mathrm{O}_{2}$ [133, 134], it was reported that melatonin does not directly scavenge $\mathrm{H}_{2} \mathrm{O}_{2}$ in vitro [135]. Fowler et al. [135] claim that the direct interaction of melatonin with $\mathrm{H}_{2} \mathrm{O}_{2}$ in vitro occurs only when traces of transition metal ions are present in the reaction medium, Thus, in vivo, in conditions under tissue injury, the presence of transition metal ions may favor the reaction between melatonin and $\mathrm{H}_{2} \mathrm{O}_{2}$. In addition, the two metabolites, cyclic 3-hydroxymelatonin and AFMK, may also function as scavengers of toxic reactants [136-138]. However, other melatonin metabolites, $N$-acetyl-5-methoxykynuramine (AMK) and 6-hydroxymelatonin, are also capable of neutralizing some ROS. A cascade of scavenging reaction seems to be initiated by melatonin and thus could explain the high efficacy of melatonin in reducing oxidative damage [138]. Other ROS have been reported to be scavenged by melatonin [138]. Interestingly, melatonin can also react with peroxynitrite producing several metabolites including $N$-nitrosomelatonin [138-141].

Besides its ability to directly scavenge ROS and RNS, melatonin has a number of indirect actions by which it may reduce oxidative/nitrosative stress. It has been reported that melatonin can increase the SOD and catalase activities and induces the expression and activity of GPx and GRd, regulating the redox cycle of glutathione [142-147]. The regulation of glutathione system by melatonin is also reflected by the stimulation of the rate limiting enzyme in glutathione synthesis, $\gamma$-glutamylcysteine synthase [148]. Moreover, melatonin can reduce the expression and activity of iNOS and, thereby, decrease the levels of NO and peroxynitrite [149, 150]. Therefore, the actions of melatonin can be classified according to receptor- and non-receptor-mediated processes [151] depending of its direct and indirect action. Receptormediated effects of melatonin involve both membrane and nuclear receptors [152-155].
Based on all these properties of melatonin, the indolamine has been used in a wide variety of experimental conditions and cellular and animal models of diseases. Especially relevant are the studies in which mitochondrial function is compromised by the toxic effects of ROS and RNS. The ability of melatonin to influence mitochondrial homeostasis was initially tested in vivo. In this study it was shown that melatonin administered to normal rats significantly increased the activities of the C-I and C-IV of the mitochondrial respiratory chain measured in isolated mitochondria obtained from brain and liver, whereas C-II and C-III were unaffected [156]. Melatonin also counteracted ruthenium red-induced inhibition of C-I and C-IV in brain and liver mitochondria when melatonin was given simultaneously with ruthenium red [156].

To further test the antioxidant potency of melatonin against mitochondrial oxidative stress, in vitro experiments using isolated mitochondria prepared from rat brain and liver were performed. Oxidative stress was induced by incubation of these mitochondria with t-butyl hydroperoxide (t-BHP), which oxidizes pyridine nucleotides, depletes the mitochondrial GSH pool and inhibits both GPx and GRd activities [157]. In this situation, $100 \mathrm{nM}$ melatonin counteracted these effects, by restoring basal levels of GSH and the normal activities of both GPx and GRd. N-acetyl cysteine (NAC) and vitamins $\mathrm{E}$ and $\mathrm{C}$ were unable to exert any significant effect on t-BHP-induced oxidative stress in mitochondria despite the high doses of these compounds used [158]. Interestingly, melatonin increased the activity of the C-I and C-IV in a dose-dependent manner, the effect being significant at $1 \mathrm{nM}$ melatonin [158]. Melatonin was also able to counteract the cyanide-induced inhibition of C$\mathrm{IV}$, restoring the levels of cyt $\mathrm{a}+\mathrm{a}_{3}$. Moreover, melatonin increased the activity of C-I separated by blue native polyacrylamide gel electrophoresis (PAGE). The effects of melatonin are of likely physiological significance since the indoleamine increased the mitochondria respiratory chain activity coupled to OXPHOS, which was reflected in an elevated ATP synthesis, either in normal mitochondria or in mitochondria depleted of ATP by cyanide incubation [127, 159].

Recently, a study performed in vitro with normal mitochondria addressed some of the mechanisms involved in the actions of melatonin on this organelle [127]. Using highresolution respirometry, rat liver mitochondria were analyzed for oxygen consumption, ROS generation, membrane potential, ROS generation, and activities of mitochondrial complexes. Melatonin decreased oxygen consumption in the presence of ADP in a concentration-dependent manner; it reduced the membrane potential and, consequently inhibited the production of $\mathrm{O}_{2}^{-} \cdot$ and $\mathrm{H}_{2} \mathrm{O}_{2}$. At the same time, melatonin maintained the respiratory control ratio (RCR) and the efficiency of oxidative phosphorylation and ATP synthesis while increasing the activity of the respiratory complexes (mainly C-I, C-III, and C-IV). Kinetic experiments showed that mitochondria take up melatonin in a time- and concentration-dependent manner and thus, the effects of melatonin on this organelle were due to its presence within the mitochondria [127]. These data support the hypothesis that melatonin participates in the physiological regulation of mitochondrial homeostasis. 
The effect of melatonin in the reduction of nitrosative stress and mitochondrial damage has been amply studied in animal models of sepsis. The administration of pharmacological doses of melatonin in rodents with sepsis induced by lipopolysacharide injection or cecal ligation and puncture (CLP) produced a decrease in the expression and activity of iNOS, and consequently nitrite levels, nitrosative/oxidative stress and mitochondrial function were normalized in muscle tissues and liver [51-54, 149, 160]. Likewise, the survival of CLP mice treated with melatonin increased significantly. Interestingly, the increase of iNOS expression was more pronounced in aged (18 m.o.) than young rats $(3 \mathrm{~m}$.o. $)$, but melatonin was able to reduce the expression in both groups $[51,161]$. Because of the efficacy of melatonin in the treatment of experimental sepsis, Gitto and co-workers tested this treatment for sepsis in human premature newborns [162]. Twenty newborns diagnosed with sepsis were randomly divided into 2 groups of 10 infants each; all were given conventional antibiotic therapy but 10 were also supplemented with 2 doses of $10 \mathrm{mg}$ oral melatonin within the first 12 hours after after diagnosis, separated by a 1-hour interval. Melatonin improved the clinical outcome of the septic newborns as judged by measurement of sepsis-related serum parameters after 24 and $48 \mathrm{~h}$. Three of 10 septic children who were not treated with melatonin died within 72 $\mathrm{h}$ after diagnosis of sepsis; none of the 10 septic newborns treated with melatonin died [162]. Therefore, melatonin may assist considerably in reducing the mortality of sepsis.

In a series of studies, we have demonstrated the efficacy of melatonin to prevent oxidative damage and mitochondrial dysfunction in aging. In SAMP8 mice, chronic melatonin administration in the drinking water for 9 months $(10 \mathrm{mg} / \mathrm{kg}$ b.w.) completely prevented the mitochondrial impairment in heart, diaphragm, skeletal muscle, and brain, maintaining or even increasing ATP production [105-107, 163]. Likewise, melatonin prevented the increase of mitochondrial LPO and increased GPx and GRd activities normalizing the GSSG/ GSH ratio [105-107, 163]. Moreover, melatonin prevented the age-dependent increase in serum pro-inflammatory cytokines in SAM mice [108], and age-dependent nitrosative status in mitochondria was also prevented by melatonin administration [107, 108]. All these effects of melatonin treatment led to a significant increase of both half-life and life span of SAM mice [163]. Although melatonin treatment increased survival in SAMR1 mice, the main effect of the indoleamine was produced in SAMP8 mice, in which the survival was increased by 4 months, so that the animals reached the same age as SAMR1 animals [163]. This is an interesting finding, and support experimental data from other pathophysiological conditions, reporting that melatonin is more efficient in the regulation of mitochondrial function when it is impaired.

Since many of neurodegenerative diseases share a common pathway of mitochondrial dysfunction, the properties of melatonin are also of interest for the treatment of these disorders. Although it was recently suggested that PD could be an endocrine disorder of the endogenous melatonin [164], most of the experimental data supports the neuroprotective properties of the indoleamine on this disease. In mouse models of PD induced by MPTP melatonin administration normalized complex I activity and oxidative status in mitochondria from substantia nigra and striatum. Looking for the targets of melatonin action, it was recently shown that melatonin reduced the activity of the mitochondrial iNOS (imtNOS), thus decreasing mitochondrial NO• levels, preventing the respiratory inhibition produced by $\mathrm{NO} \bullet$ at the level of complex IV [165]. Melatonin also protects against excitotoxicity by reducing the autoxidation of dopamine (DA) which occurs in PD [166]. These effects were demonstrated in MPTP-induced PD in mice [167, 168] and in PC12 cells incubated with 6-hydroxydopamine [169]. Melatonin also abrogated cell death induced by cysteamine pretreatment of the PC12 cells; cystamine treatment involves mitochondrial iron sequestration [170]. The age-associated accumulation of redox-active iron in subcortical astrocytes may facilitate the bioactivation of DA to neurotoxic free radical intermediates and thereby predispose the nervous system to PD and other neurodegenerative diseases. In rats injected with kainic acid to produce excitotoxicity-induced apoptotic cell death, melatonin significantly attenuated apoptosis, an effect linked to the reduction in oxidative damage and an increased GSH content [171]. In a spontaneous, ageinduced model of apoptosis using cerebellar granule cells, it was shown that melatonin and $\mathrm{Ca}^{2+}$-channel blockers such as amlodipine, inhibited spontaneous apoptosis [172]. This antagonism between melatonin and $\mathrm{Ca}^{2+}$-channels was also demonstrated in electrophysiological and binding experiments [173]. Striatal neurons growing in low density culture in serum-free medium and in the absence of glia die within 3 days by apoptosis. The presence of melatonin rescues striatal neurons from impending cell death, which may have important consequences in neurodegenerative diseases involving nigrostriatal pathway as in PD [174].

In $\mathrm{AD}$ patients melatonin levels are decreased in blood and cerebrospinal fluid (CSF) and that reduction seems to parallel the progression of AD neuropathology $[175,176]$. Moreover, CSF melatonin levels are already decreased in pre-clinical AD individuals [175]. The administration of melatonin has been tested in order to reduce the neurodegenerative manifestations in $\mathrm{AD}$ [177]. When neuroblastoma cells were incubated with $\mathrm{A} \beta$, more than $80 \%$ of the neurons died due to apoptosis, but the presence of melatonin reduced cellular death and DNA damage in a dose-dependent manner [178]. In human platelets, melatonin also protected against A $\beta$-induced damage $[179,180]$. Recently, melatonin treatment has been tested in the APP + presenilin-1 double transgenic ( $\mathrm{Tg}$ ) mouse, which is considered a mouse model with characteristics of the neuropathology of AD [181]. Melatonin administered in the drinking water $(100 \mathrm{mg} / \mathrm{L}$ water) for four months was able to protect $\mathrm{AD}$ mice from cognitive impairment in a variety of tasks of working memory, spatial reference learning/ memory, and basic mnemonic function. Immunoreactive $A \beta$ deposition was significantly reduced in hippocampus $(43 \%)$ and entorhinal cortex (37\%) of melatonin-treated AD mice. The levels of TNF- $\alpha$ was decreased in hippocampus of AD mice treated with melatonin, as well as the cortical mRNA expression of SOD-1, GPx and catalase. Taken the results together, the authors suggested that melatonin's cognitive benefits could involve its anti-A $\beta$ aggregation, anti-inflammatory, and/or antioxidant properties [181]. In AD patients, melatonin has been able to stabilize cognitive function over a $2-3$ year period $[180,182]$. An additional retrospective study reported that individuals with mild cognitive impairment 
given melatonin for sleep enhancement also showed significantly better cognitive performance in two widely utilized cognitive assessment tests [183].

\section{MELATONIN, MITOCHONDRIA, AND NEURAL STEM CELLS}

A role of mitochondria in stem cell proliferation and/or differentiation begins to have experimental support, but the role of melatonin remains unclear. One can presume that, in view of the specific and significant effects of melatonin on mitochondrial physiology, the indoleamine may also affect mitochondrial physiology in stem cells. It has been shown in a recent study that the differentiation of multipotent haematopoietic progenitor cells from Drosophila can be regulated by the levels of ROS in that cells [117]. Then, the antioxidant capacity of melatonin could modulates the proliferative and differentiation potential. Related to that, it was recently reported that melatonin modulates the proliferative and differentiative ability of the neural stem cells from fetal mouse brain, depending on concentration and exposure-timing [184]. When applied during the proliferation period, pharmacological concentrations of melatonin (1-100 $\mu \mathrm{M})$ applied during the proliferation period, caused a decrease in cell division. Interestingly, neural differentiation of these cells increased without affecting astroglial differentiation. Other data point towards a net hippocampal neurogenesis in adult mice by melatonin [185]. The effects of melatonin on neural proliferation and differentiation might partly result from melatonin's activity in mitochondria and thus, additional studies are required to uncover underlying melatonin's actions on neural stem cells. Finally, if oxidative and nitrosative environment in the aged brain and its interaction with mitochondrial function are critical factors for the long-term survival and phenotypic stability of stem cell-derived neurons or glial cells newly generated or transplanted in some brain areas [186], melatonin could, thus, be of potential utility in order to increase the survival of these cells.

\section{CONCLUDING REMARKS}

Due to the multiple functions of the mitochondria in the cell, any alteration in this organelle might have a considerable impact on the functioning of the cell and, potentially, the entire organism. One of the main aspects here revised regarding mitochondrial dysfunction is the participation of ROS/RNS in mitochondrial pathologies. Although no convincingly effective treatment is to date available for most mitochondrial-dependent diseases, an interesting and, perhaps, promising therapeutic approach might consist in the use of free radical scavengers and/or antioxidants to prevent/ counteract the damage induced by ROS/RNS. In this regard, melatonin treatment may become a first-line therapy because of its multiple actions on mitochondria. In fact, mitochondria take up melatonin in a concentration- and time-dependent manner and, once inside the organelle, melatonin exerts a series of actions with the consequence of maintaining their bioenergetic capacity. Melatonin increases the activity of the respiratory chain and the ATP production, reducing at the same time the $\mathrm{O}_{2}$ consumption. Consequently, melatonin avoids an excess of ROS, preventing PTP opening and apoptosis. Additionally, melatonin also prevents changes in the $\Delta \psi_{\mathrm{m}}$ that could account for bioenergetic alteration and PTP opening. Due to the lack of side effects of melatonin, the indoleamine is an excellent candidate for the cotreatment of many of the mitochondrial-related diseases. The recent findings on the role of mitochondria on stem cell differentiation open a promising line of research for melatonin.
ABBREVIATIONS
8 -OHdG = 8-hydroxy-2'-deoxyguanosine
$\mathrm{A} \beta=$ Amyloid $\beta$
$\mathrm{AD}=$ Alzheimer disease
AFMK $=N^{1}$-acetyl- $N^{2}$-formyl-5-methoxykynuramine
AMK $=N$-acetyl-5-methoxykynuramine
C-I $=$ Complex I
C-II $=$ Complex III
C-III $=$ Complex III
C-IV $=$ Complex IV
$\mathrm{C}-\mathrm{V}=$ Complex $\mathrm{V}$
CLP $=$ Cecal ligation and puncture
$\mathrm{CoQ}_{10}=$ Coenzyme Q10
COX $=$ Cytochrome $c$ oxidase
$\mathrm{DA}=$ Dopamine
ESC $=$ Embryonic stem cells
GPx = Glutathione peroxidase
GRd = Glutathione reductase
$\mathrm{GSH}=$ Glutathione (reduced form)
GSSG = Glutathione (oxidized form)
iNOS $=$ Inducible nitric oxide synthase
LPO = Lipid peroxidatios
MPTP = 1-Methyl-4-phenyl-1,2,3,6- tetrahydropyridine
mtDNA $=$ Mitochondrial DNA
nNOS $=$ Neuronal nitric oxide synthase
OXPHOS $=$ Oxidative phosphorylation
PD $=$ Parkinson disease
POLG $=$ Mitochondrial DNA polymerase $\gamma$
PTP $=$ Permeability transition pore
RCR $=$ Respiratory control ratio
RNS $=$ Reactive nitrogen species
ROS $=$ Reactive oxygen species
SAMR = Senescence accelerated mouse - resistant
$\mathrm{SAMP}=$ Senescence accelerated mouse - prone 


$$
\begin{array}{ll}
\mathrm{SOD} & =\text { Superoxide dismutase } \\
t \text {-BHP } & =t \text {-butyl hydroperoxide } \\
\mathrm{TP} & =\text { Thymidine phosphorylase } \\
\mathrm{UCP} & =\text { Uncoupling proteins }
\end{array}
$$

\section{ACKNOWLEDGEMENTS}

This study was partially supported by grants from the Instituto de Salud Carlos III (G03/137, RD06/0013/0008, PI08-1664), and from the Consejería de Innovación, Ciencia y Empresa, Junta de Andalucía (P07-CTS-03135 and CTS101).

\section{REFERENCES}

[1] Anderson S, Bankier AT, Barrell BG, et al. Sequence and organization of the human mitochondrial genome. Nature 1981; 290(5806): 457-65.

[2] Falkenberg M, Larsson NG, Gustafsson CM. DNA replication and transcription in mammalian mitochondria. Annu Rev Biochem 2007; 76: 679-99.

[3] Attardi G, Schatz G. Biogenesis of mitochondria. Annu Rev Cell Biol 1988; 4: 289-333.

[4] Houtkooper RH, Vaz FM. Cardiolipin, the heart of mitochondrial metabolism. Cell Mol Life Sci 2008; 65(16): 2493-506.

[5] Acuna-Castroviejo D, Martin M, Macias M, et al. Melatonin, mitochondria, and cellular bioenergetics. J Pineal Res 2001; 30(2): 65-74.

[6] Mitchell P. Chemiosmotic coupling in oxidative and photosynthetic phosphorylation. Biol Rev Camb Philos Soc 1966; 41(3): 445-502.

[7] Diehl AM, Hoek JB. Mitochondrial uncoupling: role of uncoupling protein anion carriers and relationship to thermogenesis and weight control "the benefits of losing control". J Bioenerg Biomembr 1999; 31(5): 493-506.

[8] Klingenberg M. Uncoupling protein--a useful energy dissipator. J Bioenerg Biomembr 1999; 31(5): 419-30.

[9] Klingenspor M, Fromme T, Hughes DA Jr, et al. An ancient look at UCP1. Biochim Biophys Acta 2008; 1777(7-8): 637-41.

[10] Boss O, Hagen T, Lowell BB. Uncoupling proteins 2 and 3: potential regulators of mitochondrial energy metabolism. Diabetes 2000; 49(2): 143-56.

[11] Muzzin P, Boss O, Giacobino JP. Uncoupling protein 3: its possible biological role and mode of regulation in rodents and humans. $\mathrm{J}$ Bioenerg Biomembr 1999; 31(5): 467-73.

[12] Brand MD, Esteves TC. Physiological functions of the mitochondrial uncoupling proteins UCP2 and UCP3. Cell Metab 2005; 2(2): 85-93.

[13] Echtay KS, Winkler E, Klingenberg M. Coenzyme Q is an obligatory cofactor for uncoupling protein function. Nature 2000; 408(6812): 609-13.

[14] Echtay KS, Winkler E, Frischmuth K, Klingenberg M. Uncoupling proteins 2 and 3 are highly active $\mathrm{H}(+)$ transporters and highly nucleotide sensitive when activated by coenzyme Q (ubiquinone). Proc Natl Acad Sci USA 2001; 98(4): 1416-21.

[15] Jaburek M, Garlid KD. Reconstitution of recombinant uncoupling proteins: UCP1, -2 , and -3 have similar affinities for ATP and are unaffected by coenzyme Q10. J Biol Chem 2003; 278(28): 2582531.

[16] Sluse FE, Jarmuszkiewicz W, Navet R, Douette P, Mathy G, SluseGoffart CM. Mitochondrial UCPs: new insights into regulation and impact. Biochim Biophys Acta 1757(5-6): 480-5.

[17] Dlaskova A, Hlavata L, Jezek J, Jezek P. Mitochondrial Complex I superoxide production is attenuated by uncoupling. Int $\mathrm{J}$ Biochem Cell Biol 2008; 40(10): 2098-109.

[18] Gottlieb RA. Mitochondria: execution central. FEBS Lett 2000; 482(1-2): 6-12.

[19] Green DR. Apoptotic pathways: the roads to ruin. Cell 1998; 94(6): 695-8.

[20] Zago EB, Castilho RF, Vercesi AE. The redox state of endogenous pyridine nucleotides can determine both the degree of mitochondrial oxidative stress and the solute selectivity of the permeability transition pore. FEBS Lett 2000; 478(1-2): 29-33.

[21] Fontaine E, Bernardi P. Progress on the mitochondrial permeability transition pore: regulation by complex I and ubiquinone analogs. J Bioenerg Biomembr 1999; 31(4): 335-45.

[22] DiMauro S, Schon EA. Mitochondrial disorders in the nervous system. Ann Rev Neurosci 2008; 31: 91-123.

[23] Schapira AH. Mitochondrial disease. Lancet 2006; 368(9529): 7082.

[24] Jonckheere AI, Hogeveen M, Nijtmans LG, et al. A novel mitochondrial ATP8 gene mutation in a patient with apical hypertrophic cardiomyopathy and neuropathy. J Med Genet 2008; 45(3): 129-33.

[25] Barel O, Shorer Z, Flusser H, et al. Mitochondrial complex III deficiency associated with a homozygous mutation in UQCRQ. Am J Hum Genet 2008; 82(5): 1211-6.

[26] Massa V, Fernandez-Vizarra E, Alshahwan S, et al. Severe infantile encephalomyopathy caused by a mutation in COX6B1, a nucleusencoded subunit of cytochrome c oxidase. Am J Hum Genet 2008; 82(6): 1281-9.

[27] Vives-Bauza C, Gonzalo R, Manfredi G, Garcia-Arumi E, Andreu AL. Enhanced ROS production and antioxidant defenses in cybrids harbouring mutations in mtDNA. Neurosci Lett 2006; 391(3): 13641.

[28] Robinson BH, Petrova-Benedict R, Buncic JR, Wallace DC Nonviability of cells with oxidative defects in galactose medium: a screening test for affected patient fibroblasts. Biochem Med Metab Biol 1992; 48(2): 122-6.

[29] Floreani M, Napoli E, Martinuzzi A, et al. Antioxidant defences in cybrids harboring mtDNA mutations associated with Leber's hereditary optic neuropathy. FEBS J 2005; 272(5): 1124-35.

[30] Baracca A, Sgarbi G, Mattiazzi M, et al. Biochemical phenotypes associated with the mitochondrial ATP6 gene mutations at nt8993. Biochim Biophys Acta 2007; 1767(7): 913-9.

[31] Quinzii CM, Lopez LC, Naini A, DiMauro S, Hirano M. Human CoQ10 deficiencies. Biofactors 2008; 32(1-4): 113-8.

[32] Lopez LC, Schuelke M, Quinzii CM, et al. Leigh syndrome with nephropathy and CoQ10 deficiency due to decaprenyl diphosphate synthase subunit 2 (PDSS2) mutations. Am J Hum Genet 2006; 79(6): 1125-9.

[33] Quinzii C, Naini A, Salviati L, et al. A mutation in parahydroxybenzoate-polyprenyl transferase (COQ2) causes primary coenzyme Q10 deficiency. Am J Hum Genet 2006; 78(2): 345-9.

[34] Mollet J, Giurgea I, Schlemmer D, et al. Prenyldiphosphate synthase, subunit 1 (PDSS1) and OH-benzoate polyprenyltransferase (COQ2) mutations in ubiquinone deficiency and oxidative phosphorylation disorders. J Clin Invest 2007; 117(3): 765-72.

[35] Diomedi-Camassei F, Di Giandomenico S, Santorelli FM, et al. COQ2 nephropathy: a newly described inherited mitochondriopathy with primary renal involvement. J Am Soc Nephrol 2007; 18(10): 2773-80.

[36] Duncan AJ, Bitner-Glindzicz M, Meunier B, et al. A nonsense mutation in COQ9 causes autosomal-recessive neonatal-onset primary coenzyme Q10 deficiency: a potentially treatable form of mitochondrial disease. Am J Hum Genet 2009; 84(5): 558-66.

[37] Quinzii CM, Lopez LC, Von-Moltke J, et al. Respiratory chain dysfunction and oxidative stress correlate with severity of primary CoQ10 deficiency. FASEB J 2008; 22(6): 1874.

[38] Lagier-Tourenne C, Tazir M, Lopez LC, et al. ADCK3, an ancestral kinase, is mutated in a form of recessive ataxia associated with coenzyme Q10 deficiency. Am J Hum Genet 2008; 82(3): 661-72.

[39] Quinzii CM, Kattah AG, Naini A, et al. Coenzyme Q deficiency and cerebellar ataxia associated with an aprataxin mutation. Neurology 2005; 64(3): 539-41.

[40] Gempel K, Topaloglu H, Talim B, et al. The myopathic form of coenzyme Q10 deficiency is caused by mutations in the electrontransferring-flavoprotein dehydrogenase (ETFDH) gene. Brain 2007; 130(Pt 8): 2037-44.

[41] Ghezzi D, Goffrini P, Uziel G, et al. SDHAF1, encoding a LYR complex-II specific assembly factor, is mutated in SDH-defective infantile leukoencephalopathy. Nat Genet 2009.

[42] Nishino I, Spinazzola A, Hirano M. Thymidine phosphorylase gene mutations in MNGIE, a human mitochondrial disorder. Science 1999; 283(5402): 689-92. 
[43] Nishigaki Y, Marti R, Copeland WC, Hirano M. Site-specific somatic mitochondrial DNA point mutations in patients with thymidine phosphorylase deficiency. J Clin Invest 2003; 111(12): 1913-21.

[44] Nishigaki Y, Marti R, Hirano M. ND5 is a hot-spot for multiple atypical mitochondrial DNA deletions in mitochondrial neurogastrointestinal encephalomyopathy. Hum Mol Genet 2004; 13(1): 91-101.

[45] Lopez LC, Akman HO, Garcia-Cazorla A, et al. Unbalanced deoxynucleotide pools cause mitochondrial DNA instability in thymidine phosphorylase deficient mice. Hum Mol Genet 2009; 18(4): 714-22.

[46] Vincent JL, Zhang H, Szabo C, Preiser JC. Effects of nitric oxide in septic shock. Am J Respir Crit Care Med 2000; 161(6): 1781-5.

[47] Escames G, Acuna-Castroviejo D, Lopez LC, et al. Pharmacological utility of melatonin in the treatment of septic shock: experimental and clinical evidence. J Pharm Pharmacol 2006; 58(9): 1153-65.

[48] Boveris A, Costa LE, Poderoso JJ, Carreras MC, Cadenas E. Regulation of mitochondrial respiration by oxygen and nitric oxide. Ann N Y Acad Sci 2000; 899: 121-35

[49] Brown GC. Regulation of mitochondrial respiration by nitric oxide inhibition of cytochrome c oxidase. Biochim Biophys Acta 2001; 1504(1): 46-57.

[50] Boveris A, Alvarez S, Navarro A. The role of mitochondrial nitric oxide synthase in inflammation and septic shock. Free Radic Biol Med 2002; 33(9): 1186-93.

[51] Escames G, Leon J, Macias M, Khaldy H, Acuna-Castroviejo D. Melatonin counteracts lipopolysaccharide-induced expression and activity of mitochondrial nitric oxide synthase in rats. FASEB J 2003; 17(8): 932-4.

[52] Lopez LC, Escames G, Tapias V, Utrilla P, Leon J, AcunaCastroviejo D. Identification of an inducible nitric oxide synthase in diaphragm mitochondria from septic mice: its relation with mitochondrial dysfunction and prevention by melatonin. Int $\mathrm{J}$ Biochem Cell Biol 2006; 38(2): 267-78.

[53] Lopez LC, Escames G, Ortiz F, Ros E, Acuna-Castroviejo D. Melatonin restores the mitochondrial production of ATP in septic mice. Neuro Endocrinol Lett 2006; 27(5): 623-30.

[54] Escames G, Lopez LC, Ortiz F, et al. Attenuation of cardiac mitochondrial dysfunction by melatonin in septic mice. FEBS J 2007; 274(8): 2135-47.

[55] Brealey D, Brand M, Hargreaves I, et al. Association between mitochondrial dysfunction and severity and outcome of septic shock. Lancet 2002; 360(9328): 219-23.

[56] Fredriksson K, Hammarqvist F, Strigard K, et al. Derangements in mitochondrial metabolism in intercostal and leg muscle of critically ill patients with sepsis-induced multiple organ failure. Am J Physiol Endocrinol Metab 2006; 291(5): E1044-E1050.

[57] Schapira AH. Mitochondrial involvement in Parkinson's disease, Huntington's disease, hereditary spastic paraplegia and Friedreich's ataxia. Biochim Biophys Acta 1999; 1410(2): 159-70.

[58] Luoma P, Melberg A, Rinne JO, et al. Parkinsonism, premature menopause, and mitochondrial DNA polymerase gamma mutations: clinical and molecular genetic study. Lancet 2004; 364(9437): 87582.

[59] Davidzon G, Greene P, Mancuso M, Klos KJ, Ahlskog JE, Hirano $\mathrm{M}$, et al. Early-onset familial parkinsonism due to POLG mutations. Ann Neurol 2006; 59(5): 859-62.

[60] Howell N, Elson JL, Chinnery PF, Turnbull DM. mtDNA mutations and common neurodegenerative disorders. Trends Genet 2005; 21(11): 583-6.

[61] Abou-Sleiman PM, Muqit MM, Wood NW. Expanding insights of mitochondrial dysfunction in Parkinson's disease. Nat Rev Neurosci 2006; 7(3): 207-19.

[62] Torreilles F, Salman-Tabcheh S, Guerin M, Torreilles J. Neurodegenerative disorders: the role of peroxynitrite. Brain Res Brain Res Rev 1999; 30(2): 153-63.

[63] Miyako K, Kai Y, Irie T, Takeshige K, Kang D. The content of intracellular mitochondrial DNA is decreased by 1-methyl-4phenylpyridinium ion (MPP+). J Biol Chem 1997; 272(15): 9605-8.

[64] Azari NP, Pettigrew KD, Schapiro MB, et al. Early detection of Alzheimer's disease: a statistical approach using positron emission tomographic data. J Cereb Blood Flow Metab 1993; 13(3): 438-47.
[65] Mastrogiacomo F, Bergeron C, Kish SJ. Brain alpha-ketoglutarate dehydrogenase complex activity in Alzheimer's disease. J Neurochem 1993; 61(6): 2007-14.

[66] Sheu KF, Kim YT, Blass JP, Weksler ME. An immunochemical study of the pyruvate dehydrogenase deficit in Alzheimer's disease brain. Ann Neurol 1985; 17(5): 444-9.

[67] Bonilla E, Tanji K, Hirano M, Vu TH, DiMauro S, Schon EA. Mitochondrial involvement in Alzheimer's disease. Biochim Biophys Acta 1999; 1410(2): 171-82.

[68] Kish SJ, Bergeron C, Rajput A, et al. Brain cytochrome oxidase in Alzheimer's disease. J Neurochem 1992; 59(2): 776-9.

[69] Yao J, Irwin RW, Zhao L, Nilsen J, Hamilton RT, Brinton RD. Mitochondrial bioenergetic deficit precedes Alzheimer's pathology in female mouse model of Alzheimer's disease. Proc Natl Acad Sci USA 2009 ; 106(34): 14670-5.

[70] Harman D. Aging: a theory based on free radical and radiation chemistry. J Gerontol 1956; 11(3): 298-300.

[71] Miquel J, Economos AC, Fleming J, Johnson JE, Jr. Mitochondrial role in cell aging. Exp Gerontol 1980; 15(6): 575-91.

[72] DiMauro S, Tanji K, Bonilla E, Pallotti F, Schon EA. Mitochondrial abnormalities in muscle and other aging cells: classification, causes, and effects. Muscle Nerve 2002; 26(5): 597 607.

[73] Michikawa Y, Mazzucchelli F, Bresolin N, Scarlato G, Attardi G. Aging-dependent large accumulation of point mutations in the human mtDNA control region for replication. Science 1999; 286(5440): 774-9.

[74] Wang Y, Michikawa Y, Mallidis C, et al. Muscle-specific mutations accumulate with aging in critical human mtDNA control sites for replication. Proc Natl Acad Sci USA 2001; 98(7): 4022-7.

[75] Ma YS, Wu SB, Lee WY, Cheng JS, Wei YH. Response to the increase of oxidative stress and mutation of mitochondrial DNA in aging. Biochim Biophys Acta 2009; 1790(10): 1021-9.

[76] Trifunovic A, Wredenberg A, Falkenberg M, Spelbrink JN, Rovio AT, Bruder CE, et al. Premature ageing in mice expressing defective mitochondrial DNA polymerase. Nature 2004; 429(6990): 417-23.

[77] Kujoth GC, Hiona A, Pugh TD, et al. Mitochondrial DNA mutations, oxidative stress, and apoptosis in mammalian aging. Science 2005; 309(5733): 481-4.

[78] Loeb LA, Wallace DC, Martin GM. The mitochondrial theory of aging and its relationship to reactive oxygen species damage and somatic mtDNA mutations. Proc Natl Acad Sci USA 2005; 102(52): 18769-70

[79] Wei YH. Oxidative stress and mitochondrial DNA mutations in human aging. Proc Soc Exp Biol Med 1998; 217(1): 53-63.

[80] Cortopassi GA, Shibata D, Soong NW, Arnheim N. A pattern of accumulation of a somatic deletion of mitochondrial DNA in aging human tissues. Proc Natl Acad Sci USA 1992; 89(16): 7370-4.

[81] Bender A, Krishnan KJ, Morris CM, et al. High levels of mitochondrial DNA deletions in substantia nigra neurons in aging and Parkinson disease. Nat Genet 2006; 38(5): 515-7.

[82] Kraytsberg Y, Kudryavtseva E, McKee AC, Geula C, Kowall NW, Khrapko K. Mitochondrial DNA deletions are abundant and cause functional impairment in aged human substantia nigra neurons. Nat Genet 2006; 38(5): 518-20.

[83] Wei YH, Lu CY, Lee HC, Pang CY, Ma YS. Oxidative damage and mutation to mitochondrial DNA and age-dependent decline of mitochondrial respiratory function. Ann N Y Acad Sci 1998; 854: 155-70.

[84] Hayakawa M, Hattori K, Sugiyama S, Ozawa T. Age-associated oxygen damage and mutations in mitochondrial DNA in human hearts. Biochem Biophys Res Commun 1992; 189(2): 979-85.

[85] Dumont P, Burton M, Chen QM, et al. Induction of replicative senescence biomarkers by sublethal oxidative stresses in normal human fibroblast. Free Radic Biol Med 2000; 28(3): 361-73.

[86] Berneburg M, Grether-Beck S, Kurten V, et al. Singlet oxygen mediates the UVA-induced generation of the photoaging-associated mitochondrial common deletion. J Biol Chem 1999; 274(22): 15345-9.

[87] Agarwal S, Sohal RS. Differential oxidative damage to mitochondrial proteins during aging. Mech Ageing Dev 1995; 85(1): 55-63.

[88] Yan LJ, Levine RL, Sohal RS. Oxidative damage during aging targets mitochondrial aconitase. Proc Natl Acad Sci USA 1997; 94(21): 11168-72. 
[89] Yan LJ, Sohal RS. Mitochondrial adenine nucleotide translocase is modified oxidatively during aging. Proc Natl Acad Sci USA 1998; 95(22): 12896-901.

[90] Acuna CD, Escames G, Carazo A, Leon J, Khaldy H, Reiter RJ. Melatonin, mitochondrial homeostasis and mitochondrial-related diseases. Curr Top Med Chem 2002; 2(2): 133-51.

[91] de Lustig ES, Serra JA, Kohan S, Canziani GA, Famulari AL, Dominguez RO. Copper-zinc superoxide dismutase activity in red blood cells and serum in demented patients and in aging. $\mathbf{J}$ Neurol Sci 1993; 115(1): 18-25.

[92] Andersen HR, Nielsen JB, Nielsen F, Grandjean P. Antioxidative enzyme activities in human erythrocytes. Clin Chem 1997; 43(4): 562-8.

[93] Habif S, Mutaf I, Turgan N, et al. Age and gender dependent alterations in the activities of glutathione related enzymes in healthy subjects. Clin Biochem 2001; 34(8): 667-71.

[94] Pansarasa O, Bertorelli L, Vecchiet J, Felzani G, Marzatico F. Agedependent changes of antioxidant activities and markers of free radical damage in human skeletal muscle. Free Radic Biol Med 1999; 27(5-6): 617-22.

[95] Marzani B, Felzani G, Bellomo RG, Vecchiet J, Marzatico F. Human muscle aging: ROS-mediated alterations in rectus abdominis and vastus lateralis muscles. Exp Gerontol 2005; 40(12): 959-65.

[96] Takeda T, Hosokawa M, Takeshita S, et al. A new murine model of accelerated senescence. Mech Ageing Dev 1981; 17(2): 183-94.

[97] Takeda T. Senescence-accelerated mouse (SAM): a biogerontological resource in aging research. Neurobiol Aging 1999; 20(2): 105-10.

[98] Hosokawa M. A higher oxidative status accelerates senescence and aggravates age-dependent disorders in SAMP strains of mice. Mech Ageing Dev 2002; 123(12): 1553-61.

[99] Butterfield DA, Howard BJ, Yatin S, Allen KL, Carney JM. Free radical oxidation of brain proteins in accelerated senescence and its modulation by N-tert-butyl-alpha-phenylnitrone. Proc Natl Acad Sci USA 1997; 94(2): 674-8.

[100] Takeda T, Hosokawa M, Higuchi K. Senescence-accelerated mouse (SAM): a novel murine model of senescence. Exp Gerontol 1997; 32(1-2): 105-9.

[101] Liu J, Mori A. Age-associated changes in superoxide dismutase activity, thiobarbituric acid reactivity and reduced glutathione level in the brain and liver in senescence accelerated mice (SAM): a comparison with ddY mice. Mech Ageing Dev 1993; 71(1-2): 2330 .

[102] Matsugo S, Kitagawa T, Minami S, et al. Age-dependent changes in lipid peroxide levels in peripheral organs, but not in brain, in senescence-accelerated mice. Neurosci Lett 2000; 278(1-2): 105-8.

[103] Nomura Y, Wang BX, Qi SB, Namba T, Kaneko S. Biochemical changes related to aging in the senescence-accelerated mouse. Exp Gerontol 1989; 24(1): 49-55.

[104] Yarian CS, Rebrin I, Sohal RS. Aconitase and ATP synthase are targets of malondialdehyde modification and undergo an agerelated decrease in activity in mouse heart mitochondria. Biochem Biophys Res Commun 2005; 330(1): 151-6.

[105] Rodriguez MI, Carretero M, Escames G, et al. Chronic melatonin treatment prevents age-dependent cardiac mitochondrial dysfunction in senescence-accelerated mice. Free Radic Res 2007; 41(1): $15-24$.

[106] Rodriguez MI, Escames G, Lopez LC, et al. Melatonin administration prevents cardiac and diaphragmatic mitochondrial oxidative damage in senescence-accelerated mice. $\mathrm{J}$ Endocrinol 2007; 194(3): 637-43.

[107] Carretero M, Escames G, Lopez LC, et al. Long-term melatonin administration protects brain mitochondria from aging. J Pineal Res 2009; 47(2): 192-200.

[108] Rodriguez MI, Escames G, Lopez LC, et al. Chronic melatonin treatment reduces the age-dependent inflammatory process in senescence-accelerated mice. J Pineal Res 2007; 42(3): 272-9.

[109] Poderoso JJ, Carreras MC, Lisdero C, Riobo N, Schopfer F, Boveris A. Nitric oxide inhibits electron transfer and increases superoxide radical production in rat heart mitochondria and submitochondrial particles. Arch Biochem Biophys 1996 ; 328(1): 85-92.

[110] Cassina AM, Hodara R, Souza JM, et al. Cytochrome c nitration by peroxynitrite. J Biol Chem 2000; 275(28): 21409-15.
[111] Lonergan T, Bavister B, Brenner C. Mitochondria in stem cells. Mitochondrion 2007; 7(5): 289-96.

[112] Oh SK, Kim HS, Ahn HJ, et al. Derivation and characterization of new human embryonic stem cell lines: SNUhES1, SNUhES2, and SNUhES3. Stem Cells 2005; 23(2): 211-9.

[113] Cho YM, Kwon S, Pak YK, et al. Dynamic changes in mitochondrial biogenesis and antioxidant enzymes during the spontaneous differentiation of human embryonic stem cells. Biochem Biophys Res Commun 2006; 348(4): 1472-8.

[114] St John JC, Ramalho-Santos J, Gray HL, et al. The expression of mitochondrial DNA transcription factors during early cardiomyocyte in vitro differentiation from human embryonic stem cells. Cloning Stem Cells 2005; 7(3): 141-53.

[115] Kirby DM, Rennie KJ, Smulders-Srinivasan TK, et al. Transmitochondrial embryonic stem cells containing pathogenic mtDNA mutations are compromised in neuronal differentiation. Cell Prolif 2009; 42(4): 413-24.

[116] Sauer H, Wartenberg M. Reactive oxygen species as signaling molecules in cardiovascular differentiation of embryonic stem cells and tumor-induced angiogenesis. Antioxid Redox Signal 2005; 7(11-12): 1423-34.

[117] Owusu-Ansah E, Banerjee U. Reactive oxygen species prime Drosophila haematopoietic progenitors for differentiation. Nature 2009; 461(7263): 537-41.

[118] Rensing L, Ruoff P. Temperature effect on entrainment, phase shifting, and amplitude of circadian clocks and its molecular bases. Chronobiol Int 2002; 19(5): 807-64.

[119] Macias M, Rodriguez-Cabezas MN, Reiter RJ, Osuna A, AcunaCastroviejo D. Presence and effects of melatonin in Trypanosoma cruzi. J Pineal Res 1999; 27(2): 86-94.

[120] Reiter RJ. Melatonin: the chemical expression of darkness. Mol Cell Endocrinol 1991; 79(1-3): C153-C158.

[121] Tan DX, Manchester LC, Hardeland R, Lopez-Burillo S, Mayo JC, Sainz RM, et al. Melatonin: a hormone, a tissue factor, an autocoid, a paracoid, and an antioxidant vitamin. J Pineal Res 2003; 34(1): 75-8.

[122] Stefulj J, Hortner M, Ghosh M, et al. Gene expression of the key enzymes of melatonin synthesis in extrapineal tissues of the rat. $\mathrm{J}$ Pineal Res 2001; 30(4): 243-7.

[123] Reiter RJ. The pineal and its hormones in the control of reproduction in mammals. Endocr Rev 1980; 1(2): 109-31.

[124] Kennaway DJ, Wright H. Melatonin and circadian rhythms. Curr Top Med Chem 2002; 2(2): 199-209.

[125] Guerrero JM, Reiter RJ. Melatonin-immune system relationships. Curr Top Med Chem 2002; 2(2): 167-79.

[126] Acuna-Castroviejo D, Escames G, Leon J, Carazo A, Khaldy H. Mitochondrial regulation by melatonin and its metabolites. Adv Exp Med Biol 2003; 527: 549-57.

[127] Lopez A, Garcia JA, Escames G, et al. Melatonin protects the mitochondria from oxidative damage reducing oxygen consumption, membrane potential, and superoxide anion production. J Pineal Res 2009; 46(2): 188-98.

[128] Reiter RJ. Melatonin: lowering the high price of free radicals. News Physiol Sci 2000; 15: 246-50.

[129] Reiter RJ, Tan DX, Qi W, Manchester LC, Karbownik M, Calvo JR. Pharmacology and physiology of melatonin in the reduction of oxidative stress in vivo. Biol Signals Recept 2000; 9(3-4): 160-71.

[130] Poeggeler B, Saarela S, Reiter RJ, et al. Melatonin--a highly potent endogenous radical scavenger and electron donor: new aspects of the oxidation chemistry of this indole accessed in vitro. Ann N Y Acad Sci 1994; 738: 419-20.

[131] Tan DX, Manchester LC, Reiter RJ, et al. A novel melatonin metabolite, cyclic 3-hydroxymelatonin: a biomarker of in vivo hydroxyl radical generation. Biochem Biophys Res Commun 1998; 253(3): 614-20.

[132] Tan DX, Manchester LC, Reiter RJ, et al. Melatonin directly scavenges hydrogen peroxide: a potentially new metabolic pathway of melatonin biotransformation. Free Radic Biol Med 2000; 29(11): 1177-85.

[133] Carampin P, Rosan S, Dalzoppo D, Zagotto G, Zatta P. Some biochemical properties of melatonin and the characterization of a relevant metabolite arising from its interaction with $\mathrm{H} 2 \mathrm{O} 2$. J Pineal Res 2003; 34(2): 134-42.

[134] Rozov SV, Filatova EV, Orlov AA, et al. N1-acetyl-N2-formyl-5methoxykynuramine is a product of melatonin oxidation in rats. $J$ Pineal Res 2003; 35(4): 245-50. 
[135] Fowler G, Daroszewska M, Ingold KU. Melatonin does not "directly scavenge hydrogen peroxide": demise of another myth. Free Radic Biol Med 2003; 34(1): 77-83.

[136] Tan DX, Hardeland R, Manchester LC, et al. Mechanistic and comparative studies of melatonin and classic antioxidants in terms of their interactions with the ABTS cation radical. J Pineal Res 2003; 34(4): 249-59.

[137] Lopez-Burillo S, Tan DX, Mayo JC, Sainz RM, Manchester LC, Reiter RJ. Melatonin, xanthurenic acid, resveratrol, EGCG, vitamin $\mathrm{C}$ and alpha-lipoic acid differentially reduce oxidative DNA damage induced by Fenton reagents: a study of their individual and synergistic actions. J Pineal Res 2003; 34(4): 269-77.

[138] Reiter RJ, Tan DX, Mayo JC, Sainz RM, Leon J, Czarnocki Z. Melatonin as an antioxidant: biochemical mechanisms and pathophysiological implications in humans. Acta Biochim Pol 2003; 50(4): 1129-46.

[139] Zhang H, Squadrito GL, Uppu R, Pryor WA. Reaction of peroxynitrite with melatonin: A mechanistic study. Chem Res Toxicol 1999; 12(6): 526-34.

[140] Blanchard B, Pompon D, Ducrocq C. Nitrosation of melatonin by nitric oxide and peroxynitrite. J Pineal Res 2000; 29(3): 184-92.

[141] Zhang H, Squadrito GL, Pryor WA. The reaction of melatonin with peroxynitrite: formation of melatonin radical cation and absence of stable nitrated products. Biochem Biophys Res Commun 1998; 251(1): 83-7.

[142] Barlow-Walden LR, Reiter RJ, Abe M, et al. Melatonin stimulates brain glutathione peroxidase activity. Neurochem Int 1995; 26(5): 497-502.

[143] Pablos MI, Agapito MT, Gutierrez R, et al. Melatonin stimulates the activity of the detoxifying enzyme glutathione peroxidase in several tissues of chicks. J Pineal Res 1995; 19(3): 111-5.

[144] Pablos MI, Reiter RJ, Ortiz GG, et al. Rhythms of glutathione peroxidase and glutathione reductase in brain of chick and their inhibition by light. Neurochem Int 1998; 32(1): 69-75.

[145] Agapito MT, Redondo I, Plaza R, Lopez-Burillo S, Recio JM, Pablos MI. Relationships between melatonin, glutathione peroxidase, glutathione reductase, and catalase. Endogenous rhythms on cerebral cortex in Gallus domesticus. Adv Exp Med Biol 1999; 460: 377-81.

[146] Okatani Y, Wakatsuki A, Kaneda C. Melatonin increases activities of glutathione peroxidase and superoxide dismutase in fetal rat brain. J Pineal Res 2000; 28(2): 89-96.

[147] Kotler M, Rodriguez C, Sainz RM, Antolin I, Menendez-Pelaez A. Melatonin increases gene expression for antioxidant enzymes in rat brain cortex. J Pineal Res 1998; 24(2): 83-9.

[148] Urata Y, Honma S, Goto S, et al. Melatonin induces gammaglutamylcysteine synthetase mediated by activator protein-1 in human vascular endothelial cells. Free Radic Biol Med 1999; 27(78): 838-47.

[149] Crespo E, Macias M, Pozo D, et al. Melatonin inhibits expression of the inducible NO synthase II in liver and lung and prevents endotoxemia in lipopolysaccharide-induced multiple organ dysfunction syndrome in rats. FASEB J 1999; 13(12): 1537-46.

[150] Cuzzocrea S, Costantino G, Caputi AP. Protective effect of melatonin on cellular energy depletion mediated by peroxynitrite and poly (ADP-ribose) synthetase activation in a non-septic shock model induced by zymosan in the rat. J Pineal Res 1998; 25(2): 7885

[151] Reiter RJ, Tan DX, Manchester LC, Pilar Terron M, Flores LJ, Koppisepi S. Medical implications of melatonin: receptor-mediated and receptor-independent actions. Adv Med Sci 2007; 52: 11-28

[152] Conway S, Drew JE, Mowat ES, Barrett P, Delagrange P, Morgan PJ. Chimeric melatonin $\mathrm{mtl}$ and melatonin-related receptors. Identification of domains and residues participating in ligand binding and receptor activation of the melatonin $\mathrm{mtl}$ receptor. $\mathrm{J}$ Biol Chem 2000; 275(27): 20602-9.

[153] Acuna-Castroviejo D, Reiter RJ, Menendez-Pelaez A, Pablos MI, Burgos A. Characterization of high-affinity melatonin binding sites in purified cell nuclei of rat liver. J Pineal Res 1994; 16(2): 100-12.

[154] Becker-Andre M, Wiesenberg I, Schaeren-Wiemers N, et al. Pineal gland hormone melatonin binds and activates an orphan of the nuclear receptor superfamily. J Biol Chem 1994; 269(46): 28531-4.

[155] Wiesenberg I, Missbach M, Kahlen JP, Schrader M, Carlberg C. Transcriptional activation of the nuclear receptor RZR alpha by the pineal gland hormone melatonin and identification of CGP 52608 as a synthetic ligand. Nucleic Acids Res 1995; 23(3): 327-33.
[156] Martin M, Macias M, Escames G, et al. Melatonin-induced increased activity of the respiratory chain complexes I and IV can prevent mitochondrial damage induced by ruthenium red in vivo. $\mathrm{J}$ Pineal Res 2000; 28(4): 242-8.

[157] Liu H, Kehrer JP. The reduction of glutathione disulfide produced by t-butyl hydroperoxide in respiring mitochondria. Free Radic Biol Med 1996; 20(3): 433-42.

[158] Martin M, Macias M, Escames G, Leon J, Acuna-Castroviejo D. Melatonin but not vitamins $\mathrm{C}$ and $\mathrm{E}$ maintains glutathione homeostasis in t-butyl hydroperoxide-induced mitochondrial oxidative stress. FASEB J 2000; 14(12): 1677-9.

[159] Martin M, Macias M, Leon J, Escames G, Khaldy H, AcunaCastroviejo D. Melatonin increases the activity of the oxidative phosphorylation enzymes and the production of ATP in rat brain and liver mitochondria. Int J Biochem Cell Biol 2002; 34(4): 34857.

[160] Escames G, Lopez LC, Tapias V, et al. Melatonin counteracts inducible mitochondrial nitric oxide synthase-dependent mitochondrial dysfunction in skeletal muscle of septic mice. J Pineal Res 2006; 40(1): 71-8.

[161] Escames G, Lopez LC, Ortiz F, Ros E, Acuna-Castroviejo D. Agedependent lipopolysaccharide-induced iNOS expression and multiorgan failure in rats: effects of melatonin treatment. Exp Gerontol 2006; 41(11): 1165-73.

[162] Gitto E, Karbownik M, Reiter RJ, et al. Effects of melatonin treatment in septic newborns. Pediatr Res 2001; 50(6): 756-60.

[163] Rodriguez MI, Escames G, Lopez LC, et al. Improved mitochondrial function and increased life span after chronic melatonin treatment in senescent prone mice. Exp Gerontol 2008; 43(8): 749-56.

[164] Willis GL. Parkinson's disease as a neuroendocrine disorder of circadian function: dopamine-melatonin imbalance and the visual system in the genesis and progression of the degenerative process. Rev Neurosci 2008; 19(4-5): 245-316.

[165] Tapias V, Escames G, Lopez LC, et al. Melatonin and its brain metabolite N(1)-acetyl-5-methoxykynuramine prevent mitochondrial nitric oxide synthase induction in parkinsonian mice. $\mathrm{J}$ Neurosci Res 2009; 87(13): 3002-10.

[166] Khaldy H, Escames G, Leon J, Vives F, Luna JD, AcunaCastroviejo D. Comparative effects of melatonin, L-deprenyl, Trolox and ascorbate in the suppression of hydroxyl radical formation during dopamine autoxidation in vitro. J Pineal Res 2000 29(2): 100-7.

[167] Acuna-Castroviejo D, Coto-Montes A, Gaia Monti M, Ortiz GG, Reiter RJ. Melatonin is protective against MPTP-induced striatal and hippocampal lesions. Life Sci 1997; 60(2): L23-L29.

[168] Ortiz GG, Crespo-Lopez ME, Moran-Moguel C, Garcia JJ, Reiter RJ, Acuna-Castroviejo D. Protective role of melatonin against MPTP-induced mouse brain cell DNA fragmentation and apoptosis in vivo. Neuro Endocrinol Lett 2001; 22(2): 101-8.

[169] Mayo JC, Sainz RM, Antolin I, Rodriguez C. Ultrastructural confirmation of neuronal protection by melatonin against the neurotoxin 6-hydroxydopamine cell damage. Brain Res 1999; 818(2): 221-7.

[170] Frankel D, Schipper HM. Cysteamine pretreatment of the astroglial substratum (mitochondrial iron sequestration) enhances PC12 cell vulnerability to oxidative injury. Exp Neurol 1999; 160(2): 376-85.

[171] Chen ST, Chuang JI. The antioxidant melatonin reduces cortical neuronal death after intrastriatal injection of kainate in the rat. Exp Brain Res 1999; 124(2): 241-7.

[172] Mason RP, Leeds PR, Jacob RF, et al. Inhibition of excessive neuronal apoptosis by the calcium antagonist amlodipine and antioxidants in cerebellar granule cells. J Neurochem 1999; 72(4): 1448-56.

[173] Escames G, Macias M, Leon J, et al. Calcium-dependent effects of melatonin inhibition of glutamatergic response in rat striatum. J Neuroendocrinol 2001; 13(5): 459-66.

[174] Iacovitti L, Stull ND, Mishizen A. Neurotransmitters, KCl and antioxidants rescue striatal neurons from apoptotic cell death in culture. Brain Res 1999; 816(2): 276-85.

[175] Wu YH, Feenstra MG, Zhou JN, et al. Molecular changes underlying reduced pineal melatonin levels in Alzheimer disease: alterations in preclinical and clinical stages. J Clin Endocrinol Metab 2003; 88(12): 5898-906.

[176] Zhou JN, Liu RY, Kamphorst W, Hofman MA, Swaab DF. Early neuropathological Alzheimer's changes in aged individuals are 
accompanied by decreased cerebrospinal fluid melatonin levels. J Pineal Res 2003; 35(2): 125-30.

[177] Pappolla MA, Chyan YJ, Poeggeler B, et al. An assessment of the antioxidant and the antiamyloidogenic properties of melatonin: implications for Alzheimer's disease. J Neural Transm 2000; 107(2): 203-31.

[178] Pappolla MA, Sos M, Omar RA, et al. Melatonin prevents death of neuroblastoma cells exposed to the Alzheimer amyloid peptide. J Neurosci 1997; 17(5): 1683-90.

[179] Pappolla MA, Chyan YJ, Poeggeler B, et al. Alzheimer beta protein mediated oxidative damage of mitochondrial DNA: prevention by melatonin. J Pineal Res 1999; 27(4): 226-9.

[180] Brusco LI, Marquez M, Cardinali DP. Monozygotic twins with Alzheimer's disease treated with melatonin: Case report. J Pineal Res 1998; 25(4): 260-3.

[181] Olcese JM, Cao C, Mori T, et al. Protection against cognitive deficits and markers of neurodegeneration by long-term oral administration of melatonin in a transgenic model of Alzheimer disease. J Pineal Res 2009; 47(1): 82-96.

[182] Brusco LI, Marquez M, Cardinali DP. Melatonin treatment stabilizes chronobiologic and cognitive symptoms in Alzheimer's disease. Neuro Endocrinol Lett 2000; 21(1): 39-42.

[183] Furio AM, Brusco LI, Cardinali DP. Possible therapeutic value of melatonin in mild cognitive impairment: a retrospective study. J Pineal Res 2007; 43(4): 404-9.

[184] Moriya T, Horie N, Mitome M, Shinohara K. Melatonin influences the proliferative and differentiative activity of neural stem cells. J Pineal Res 2007; 42(4): 411-8.

[185] Ramirez-Rodriguez G, Klempin F, Babu H, Benitez-King G, Kempermann G. Melatonin Modulates Cell Survival of New Neurons in the Hippocampus of Adult Mice. Neuropsychopharmacology 2009; 34(9): 2180-91.

[186] Kim SU, de VJ. Stem cell-based cell therapy in neurological diseases: a review. J Neurosci Res 2009; 87(10): 2183-200.

(C) López et al.; Licensee Bentham Open.

This is an open access article licensed under the terms of the Creative Commons Attribution Non-Commercial License (http://creativecommons.org/licenses/by$\mathrm{nc} / 3.0 /$ ), which permits unrestricted, non-commercial use, distribution and reproduction in any medium, provided the work is properly cited. 